\title{
Lipopolysaccharides of Fusobacterium nucleatum and Porphyromonas gingivalis increase RANKL-expressing neutrophils in air pouches of mice
}

\author{
Ae Ri Kim ${ }^{1,2,3}$, Yun Kyong Lim ${ }^{4}$, Joong-Ki Kook ${ }^{4}$, Eun-Jung Bak ${ }^{1 *}$ and Yun-Jung Yoo ${ }^{1 *}$
}

\begin{abstract}
Increases of neutrophils and osteoclasts are pathological changes of periodontitis. RANKL is an osteoclast differentiation factor. The effect of periodontopathogen LPS on RANKL-expressing neutrophils has not been clarified yet. We evaluated numerical changes of RANKL-expressing neutrophils in air pouches of mice injected with LPSs of Fusobacterium nucleatum and Porphyromonas gingivalis. Mice with air pouches were assigned into saline (C)-, E. coli LPS- (EC LPS)-, F. nucleatum LPS (Fn LPS)-, P. gingivalis LPS (Pg LPS)-, and Fn LPS and Pg LPS (Fn + Pg LPS)-injected groups. $C D 11 b^{+} \mathrm{Ly}_{6 \mathrm{G}^{+}}$neutrophils and $\mathrm{CD} 11 \mathrm{~b}^{+} \mathrm{Ly}_{6 \mathrm{G}}{ }^{+} \mathrm{RANKL^{+ }}$ neutrophils in blood and air pouch exudates were determined by flow cytometry. In blood, compared to the C group, the Fn LPS group showed increases of CD $11 b^{+}{\text {Ly } 6 G^{+}}^{+}$neutrophils and CD $11 b^{+}{\text {Ly } 6 G^{+}}$ANNKL $^{+}$neutrophils whereas the Pg LPS group showed no significant differences. These increases in the Fn LPS group were not different to those in the Ec LPS group. In exudates, Fn LPS and Pg LPS groups showed increases of CD $11 \mathrm{~b}^{+} \mathrm{Ly}_{6 \mathrm{G}^{+}}$neutrophils and CD11 $\mathrm{b}^{+} \mathrm{Ly} 6 \mathrm{G}^{+} \mathrm{RANKL}{ }^{+}$neutrophils compared to the $C$ group. Increased levels in the Fn LPS group were not different to those in the Ec LPS group, but Pg LPS group was lower than those in the EC LPS group. In blood and exudates, the Fn + Pg LPS group showed no difference in levels of these neutrophils compared to the Ec LPS group. LPSs of F. nucleatum and $P$. gingivalis increased RANKL-expressing neutrophils although the degrees of increases were different. These suggest that periodontopathogen LPS can act as a stimulant to increase RANKL-expressing neutrophils.
\end{abstract}

Keywords: Periodontitis, Neutrophils, RANKL, Periodontopathogen

\section{Introduction}

Periodontitis is an inflammatory disease caused by several bacteria. Bacteria in subgingival biofilm was grouped into five complexes (red, orange, green, yellow, and purple complexes) by cluster analysis and community ordination technique [1]. Green, yellow, and purple complexes are initial colonizers of the biofilm [2]. Fusobacterium nucleatum is one member of the orange complex. F. nucleatum

\footnotetext{
* Correspondence: ejbak@yuhs.ac; yu618@yuhs.ac

'Department of Oral Biology, College of Dentistry, Yonsei University, Seoul, Republic of Korea

Full list of author information is available at the end of the article
}

bridges initial and later bacterial colonizers in biofilm formation [3-5]. It has virulence factors that can damage host tissue or adhere to host tissue or other bacteria [5]. Porphyromonas gingivalis is one member of the red complex that shows close relation with pocket depth and bleeding on probing [1]. P. gingivalis is considered to be a keystone pathogen that causes abnormalities in immune response $[5,6]$.

Lipopolysaccharide (LPS), endotoxin of Gram-negative bacteria, is composed of lipid A, core oligosaccharide, and O-specific polysaccharide. Detailed structures of LPS vary depending on bacterial species and, in some bacterial

(c) The Author(s). 2021, corrected publication 2021. Open Access This article is licensed under a Creative Commons Attribution 4.0 International License, which permits use, sharing, adaptation, distribution and reproduction in any medium or format, as long as you give appropriate credit to the original author(s) and the source, provide a link to the Creative Commons licence, and indicate if changes were made. The images or other third party material in this article are included in the article's Creative Commons licence, unless indicated otherwise in a credit line to the material. If material is not included in the article's Creative Commons licence and your intended use is not permitted by statutory regulation or exceeds the permitted use, you will need to obtain permission directly from the copyright holder. To view a copy of this licence, visit http://creativecommons.org/ licenses/by/4.0/. The Creative Commons Public Domain Dedication waiver (http://creativecommons.org/publicdomain/zero/1. 0/) applies to the data made available in this article, unless otherwise stated in a credit line to the data. 
species, the structures depend on the environment [7-9]. The structural variations of LPS can affect its activities [10]. Both F. nucleatum and P. gingivalis have LPS as a virulence factor. F. nucleatum LPS (Fn LPS) is a stronger stimulator for the secretion of IL- $1 \beta$ and TNF- $\alpha$ than $P$. gingivalis LPS (Pg LPS) in neutrophils, suggesting that secretion levels of cytokines induced by LPSs from various periodontopathogens might play important roles in the onset and progression of periodontal disease [11]. Receptor activator of NF- $\mathrm{kB}$ ligand (RANKL) is an osteoclast formation-inducing cytokine associated with alveolar bone resorption in periodontal diseases [12, 13]. It has been reported that RANKL expression is upregulated in osteoblasts after Pg LPS treatment [14]. In addition, it has been suggested that RANKL-expressing neutrophils are involved in osteoclast formation in chronic obstructive pulmonary disease and rheumatoid arthritis [15, 16]. However, the effect of periodontopathogen LPS on RANK L-expressing neutrophils has not been determined yet.

Neutrophils are representative inflammatory cells that express cytokines. Neutrophils derived from stem cells of bone marrow can infiltrate into infection site through circulation $[17,18]$. A previous in vivo study has shown that RANKL-expressing neutrophils are increased in air pouches of mice injected with Escherichia coli LPS (Ec LPS) [19]. Air pouch generated on the back of a mouse has been used as an in vivo model to estimate infiltration of neutrophils into stimulant-injected air pouch [20]. To determine whether periodontopathogen LPS could act as a stimulant to increase of RANKL-expressing neutrophils, RANKL-expressing neutrophils in Pg LPS and Fn LPS-injected air pouches of mice were estimated in the present study.

\section{Methods/experimental}

\section{Air pouch induction in mouse dorsum}

Eight weeks male C57BL/6 mice (Orient Bio) were kept in polypropylene cages under specific pathogen-free conditions with temperature of $22{ }^{\circ} \mathrm{C}$, humidity of $60 \%$, and a $12 \mathrm{~h} / 12 \mathrm{~h}$ of light/dark cycle. The mice were fed standard chow and provided with water ad libitum. Protocols for animal experiment were approved by the Institutional Animal Care and Use Committee of Yonsei University (Approval Number: 2017-0109 and 2018-0147).

To generate air pouch, $5 \mathrm{ml}$ of sterilized air were injected subcutaneously into the dorsum of each mouse on day 0 and then $3 \mathrm{ml}$ of additional sterile air was reinjected on day 3 (Fig. 1a) [20]. Air injections were performed under anesthesia with a mixture of Zoletil $50(30 \mathrm{mg} / \mathrm{kg}$; Virbac, Carros, France) and Rompun (10 mg/kg; Bayer Korea).

\section{LPS injection into air pouch}

Ec LPS (Sigma-Aldrich, St Louis, Mo, USA) was used as a positive control. Fn LPS (Korean Collection for Oral
Microbiology, Gwangju, Korea) and Pg LPS (Invivogen, San Diego, CA, USA) were used as periodontopathogen LPS. Three individual experiments with 3 different groups were conducted. First experiment was conducted to salineadministered control group $(\mathrm{C}, n=7)$, Ec LPSadministered alone group (Ec LPS, $n=5$ ), and Fn LPSadministered alone group (Fn LPS, $n=8$ ). Second experiment was conducted to C group $(n=6)$, Ec LPS group $(n=5)$, and Pg LPS-administered alone group (Pg LPS, $n=$ 8). Third experiment was conducted to $C$ group $(n=5)$, Ec LPS group $(n=8)$, and Fn LPS and Pg LPS-administered combination group ( $\mathrm{Fn}+$ Pg LPS, $n=7)$. In the LPS alone experiment, the concentration of LPS in Ec LPS, Fn LPS or Pg LPS group was $2 \mu \mathrm{g} / \mathrm{ml}$. In the combination experiment, the concentration of LPS was $2 \mu \mathrm{g} / \mathrm{ml}$ per bacterium in the Fn + Pg LPS group and $4 \mu \mathrm{g} / \mathrm{ml}$ in the Ec LPS group. Mice were administered LPS or saline at 6 days after the initial air injection and then were sacrificed $6 \mathrm{~h}$ later.

\section{Flow cytometry}

Immediately after sacrifice, blood sampled through cardiac perforation was transferred into ethylene diamine tetra acetic acid (EDTA) tubes. Agranulocytes and granulocytes were separated from blood using two density gradients of Histopaque-1083 and -1119 (Sigma-Aldrich) [21]. Briefly, $2 \mathrm{ml}$ of Histopaque-1083 was carefully placed on $3 \mathrm{ml}$ of Histopaque-1119. PBS and blood in the same volume were mixed, placed on Histopaque1083 , and centrifuged at $750 \times g$ for $30 \mathrm{~min}$ at room temperature. The upper layer and the lower layer of Histopaque-1083 were mixed with PBS and centrifuged at $700 \times g$ for $5 \mathrm{~min}$ at $4{ }^{\circ} \mathrm{C}$.

To collect exudates from air pouches, $2 \mathrm{ml}$ of $2 \mathrm{mM}$ EDTA was injected into air pouch of each mouse. After collected exudates were centrifuged at $300 \times \mathrm{g}$ for $5 \mathrm{~min}$ at $4{ }^{\circ} \mathrm{C}$, cells were fixed with $2 \%$ paraformaldehyde and counted with a hemocytometer. Collected cells were incubated with anti-CD16/32 antibody (Ab) for $30 \mathrm{~min}$ at $4{ }^{\circ} \mathrm{C}$ to block non-specific reactions in which anti-Ly6G and anti-RANKL Abs bind to the Fc receptor on the cell membrane. CD11b is an adhesion molecule of neutrophils that can bind to ligands on endothelial cells [22]. Ly6G, a glycosylphosphatidylinositol-linked protein, is a specific marker that distinguish neutrophils from other leukocytes [23]. The cells were incubated with FITClabeled anti-CD11b Ab, APC-labeled anti-Ly6G Ab, and PE-labeled anti-RANKL Ab (1:100 dilutions per $10^{6}$ cells; BioLegend, San Diego, CA, USA) for $1 \mathrm{~h}$ at $4{ }^{\circ} \mathrm{C}$.

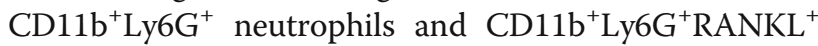
neutrophils were analyzed by flow cytometry (BD Fortessa, Becton \& Dickinson, Franklin Lakes, NJ, USA). Gating was performed using BD FACSDiva ${ }^{\mathrm{Tx}}$ software (Becton \& Dickinson, Franklin Lakes, NJ, USA) (Fig. 1b). First, live cells were gated based on scale scatter (SSC, 


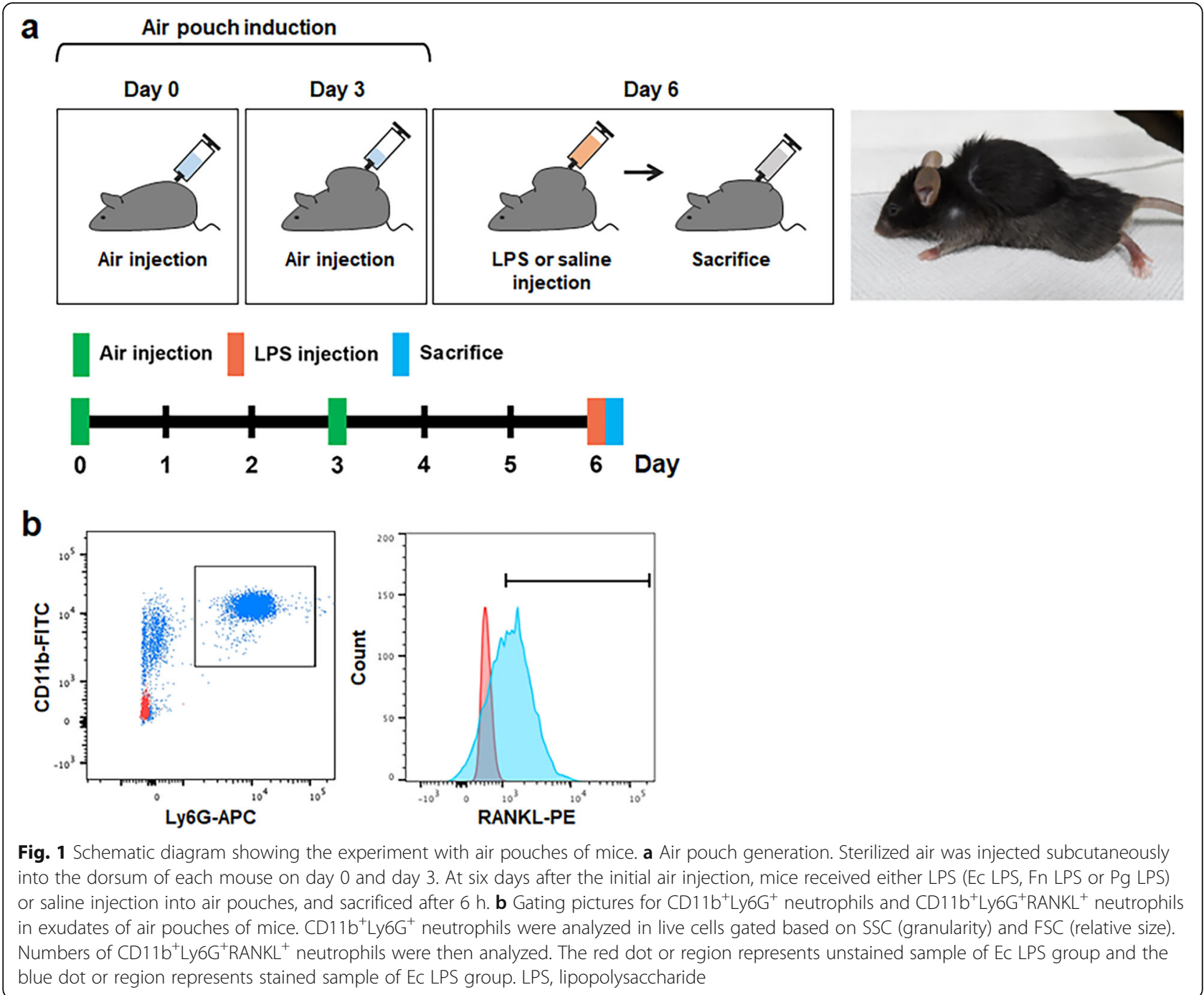

granularity) and forward scatter (FSC, relative size).

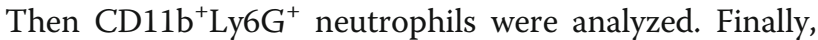

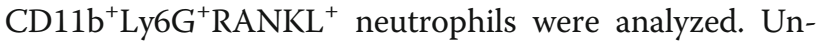
stained cells were used for gating of negative control.

\section{Statistical analysis}

The statistical significance of data was determined with the Kruskal-Wallis test $(p<0.05)$, a nonparametric test. If the differences were significant, Man-Whitney $U$ test $(p<0.017)$ was additionally performed. Data are expressed as mean \pm standard error (SE). All statistical analyses were performed using SPSS (IBM SPSS Statistics version 25, Armonk, NY, USA).

\section{Results}

Effects of Fn LPS on RANKL-expressing neutrophils in blood and exudates of air pouches

In order to evaluate the effect of Fn LPS on numbers of RANKL-expressing neutrophils in blood and exudates of air pouches of mice, numbers of $\mathrm{CD} 11 \mathrm{~b}^{+} \mathrm{Ly} 6 \mathrm{G}^{+}$neutro-

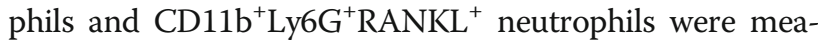
sured by flow cytometry (Fig. $2 \mathrm{a}$ and b). In blood and exudates, numbers of neutrophils and RANKL-expressing neutrophils in the Ec LPS group were higher than these in the $C$ group. In the Fn LPS group, numbers of neutrophils and RANKL-expressing neutrophils were not significantly different to the Ec LPS group. These suggest that Fn LPS can increase neutrophils and RANKL-expressing neutrophils in blood and exudates of air pouches.

\section{Effects of Pg LPS on RANKL-expressing neutrophils in blood and exudates of air pouches}

In order to evaluate the effect of Pg LPS on numbers of RANKL-expressing neutrophils in blood and exudates of air pouches, numbers of neutrophils and $\mathrm{RANKL}^{+}$ neutrophils were measured by flow cytometry (Fig. 3a and b). In blood of the Pg LPS group, numbers of neutrophils and RANKL-expressing neutrophils were 


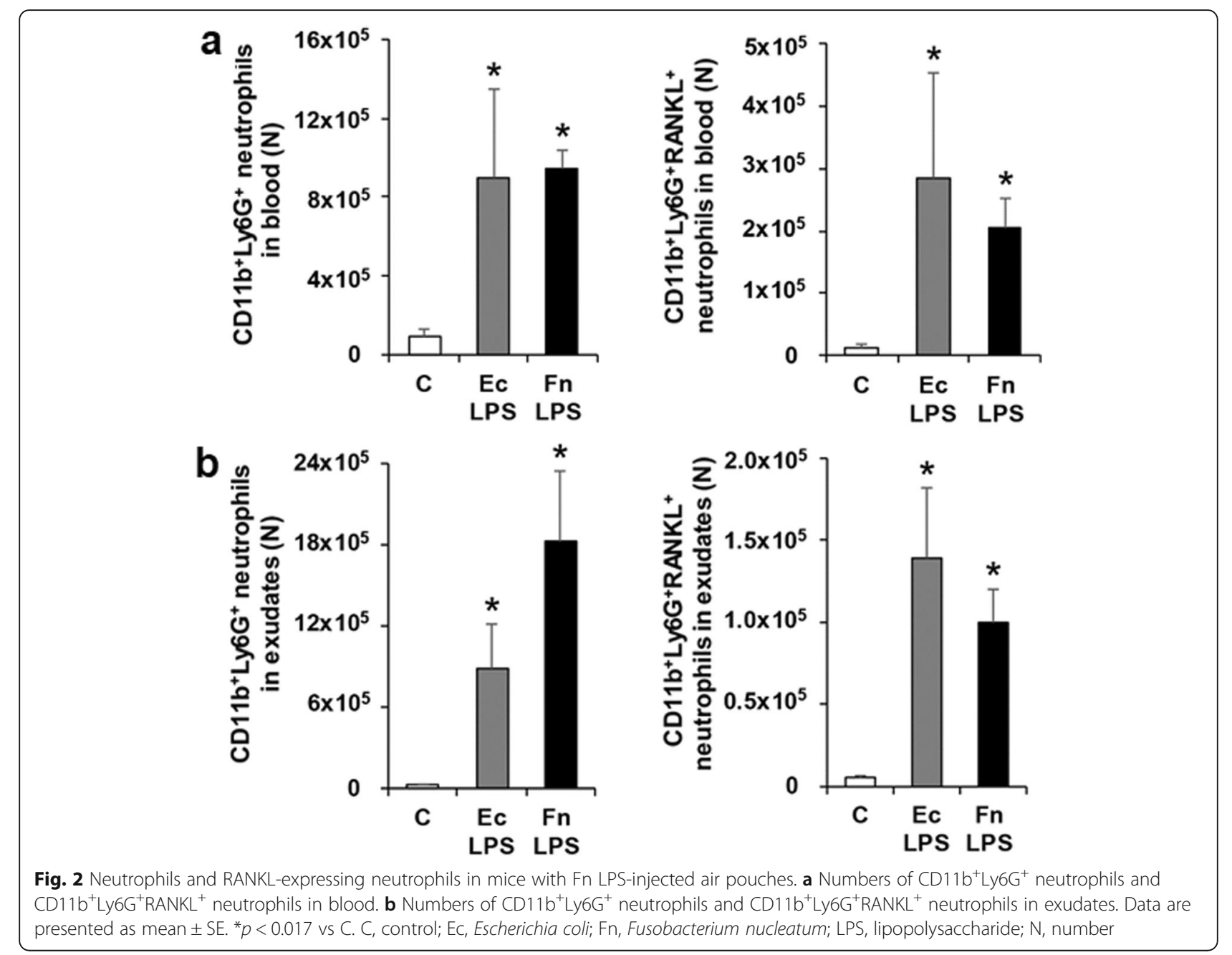

significantly lower than those in the Ec LPS group, but were not significantly different to the $C$ group (Fig. 3a). In exudates of the Pg LPS group, numbers of neutrophils and RANKL-expressing neutrophils were higher than those in the $\mathrm{C}$ group, but significantly lower than those in the Ec LPS group (Fig. 3b). These suggest that Pg LPS can increase neutrophils and RANKL-expressing neutrophils in exudates of air pouches, but not in blood.

\section{Effects of Fn LPS and Pg LPS combination on RANKL- expressing neutrophils in blood and exudates of air pouches}

To evaluate the effect of co-administration of Fn LPS and Pg LPS on numbers of neutrophils and RANKL-expressing neutrophils, Fn LPS and Pg LPS in combination were injected into air pouches of mice (Fig. $4 a$ and b). In both blood and exudates, numbers of neutrophils and RANKL-expressing neutrophils in the Fn + Pg LPS group were increased, were not significantly different to those in the Ec LPS group. These suggest that coadministration of Fn LPS and Pg LPS can increase neutrophils and RANKL-expressing neutrophils in blood and exudates of air pouches similar to Ec LPS.

\section{Discussion}

Identification of neutrophil response to periodontopathogens is necessary to understand the pathogenesis of periodontitis. This study showed that LPSs from $F$. nucleatum and $P$. gingivalis could increase RANKL-expressing neutrophils in air pouches of mice.

Lipid A of LPS is composed of disaccharide and acyl chains and its compositions are known to differ according to bacteria [7]. After Ec LPS injection, blood and air pouch exudates showed increased levels of RANKL-expressing neutrophils, similar to results of other air pouch study using neutrophil maker Ly6B [19]. These findings indicate that Ec LPS can increase RANKL-expressing neutrophils. Fn LPS has been reported to have a hexaacylated lipid A structure similar to Ec LPS $[5,10]$. In the present study, increases of RANKL-expressing neutrophils in blood and exudates after Fn LPS injection were not different to those after Ec LPS injection. This 


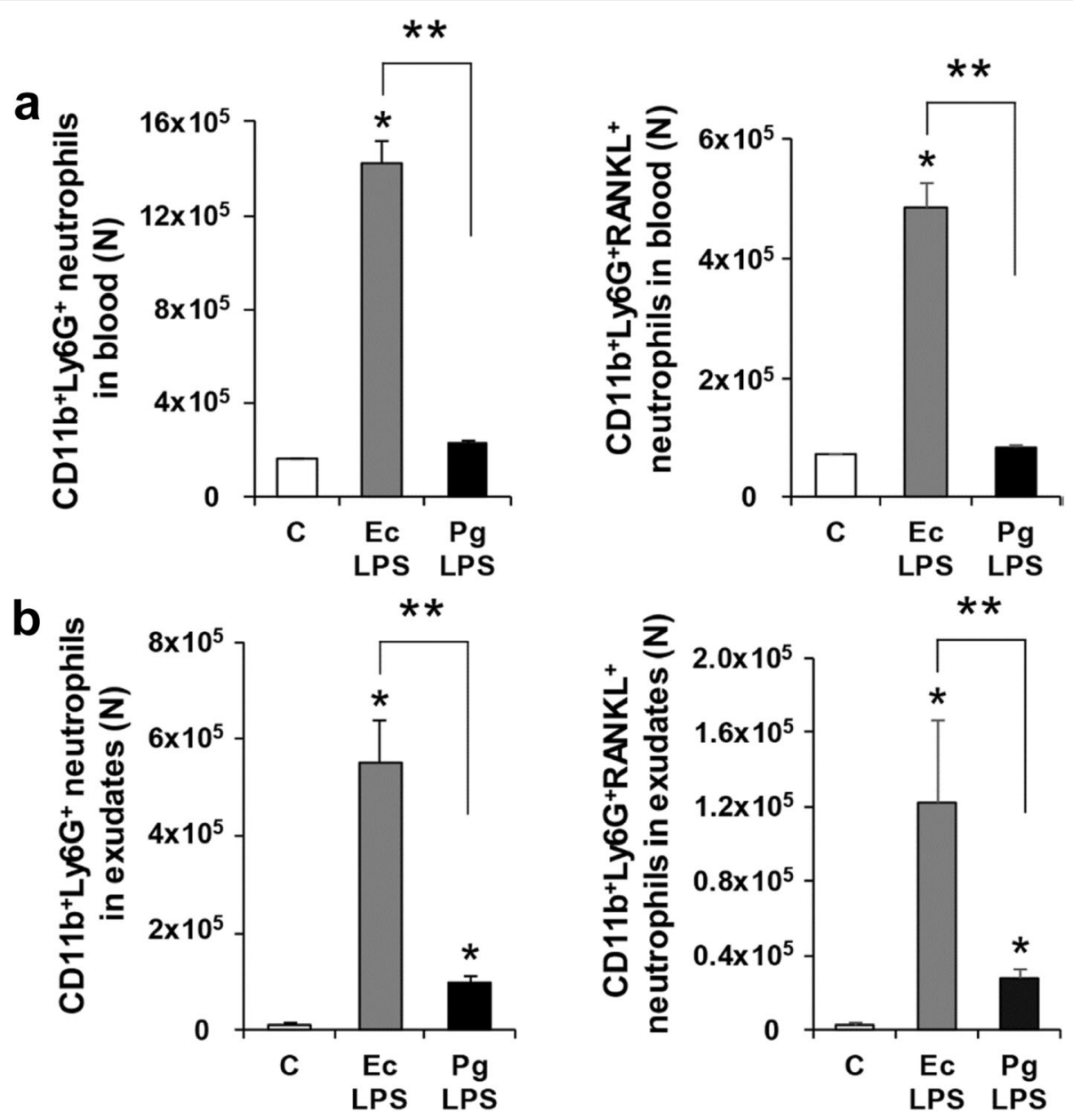

Fig. 3 Neutrophils and RANKL-expressing neutrophils in mice with Pg LPS-injected air pouches. a Numbers of CD11 $b^{+} L y 6 G^{+}$neutrophils and $C D 11 b^{+} \mathrm{Ly}_{6 G^{+}} \mathrm{RANKL}^{+}$neutrophils in blood. $\mathbf{b}$ Numbers of $\mathrm{CD} 11 \mathrm{~b}^{+} \mathrm{Ly}_{6 \mathrm{G}}{ }^{+}$neutrophils and $\mathrm{CD} 11 \mathrm{~b}^{+} \mathrm{Ly}_{6 \mathrm{G}}{ }^{+} \mathrm{RANKL} \mathrm{L}^{+}$neutrophils in exudates. Data are presented as mean \pm SE. ${ }^{*} p<0.017$ vs $C .{ }^{*} p<0.017$. C, control; Ec, Escherichia coli; Pg, Porphyromonas gingivalis; LPS, lipopolysaccharide; N, number

might be related to the structural similarity between Fn LPS and Ec LPS.

In the case of $P$. gingivalis, lipid A exhibits heterogeneous acylation patterns (penta-acylated and tetraacylated lipid A) depending on environmental conditions [9]. P. gingivalis exposed to low hemin conditions forms penta-acylated lipid A. On the other hand, its exposure to high hemin conditions forms tetra-acylated lipid A. Pg LPS with tetra-acylated lipid A different from the lipid A structure of Ec LPS was used in this study. In gingival epithelial cells, Ec LPS up-regulates expression of $\beta$-defensin, an antimicrobial molecule, but Pg tetraacylated LPS down-regulates its expression, suggesting that different lipid A structure could differentially modulate host immune response [24]. In another study, the level of TNF- $\alpha$ induced by Pg LPS in neutrophils was less than that induced by Ec LPS [25]. In the present study, Pg LPS increased RANKL-expressing neutrophils less than Ec LPS. Thus, effects of Pg LPS and Ec LPS on RANKL-expressing neutrophils were different. A previous study has shown that Fn LPS can stimulate more IL$1 \beta$ secretion in neutrophils than Pg LPS [11]. These suggest that neutrophil responses to Fn LPS injection and Pg LPS injection might be different. Taken together, LPS from $F$. nucleatum and $P$. gingivalis can act as stimulants to increase RANKL-expressing neutrophils, although their abilities might be different.

Periodontitis is a polymicrobial infectious disease $[1,26]$. Thus, we administered Fn LPS and Pg LPS simultaneously to air pouches of mice. Numbers of RANKL-expressing neutrophils in blood and exudates were increased in the group treated with a combination of Fn LPS and Pg LPS, similar to those in the group treated with Ec LPS. Our results confirmed that RANKL-expressing neutrophils were increased in the presence of two bacterial LPSs, suggesting that RANKL- 

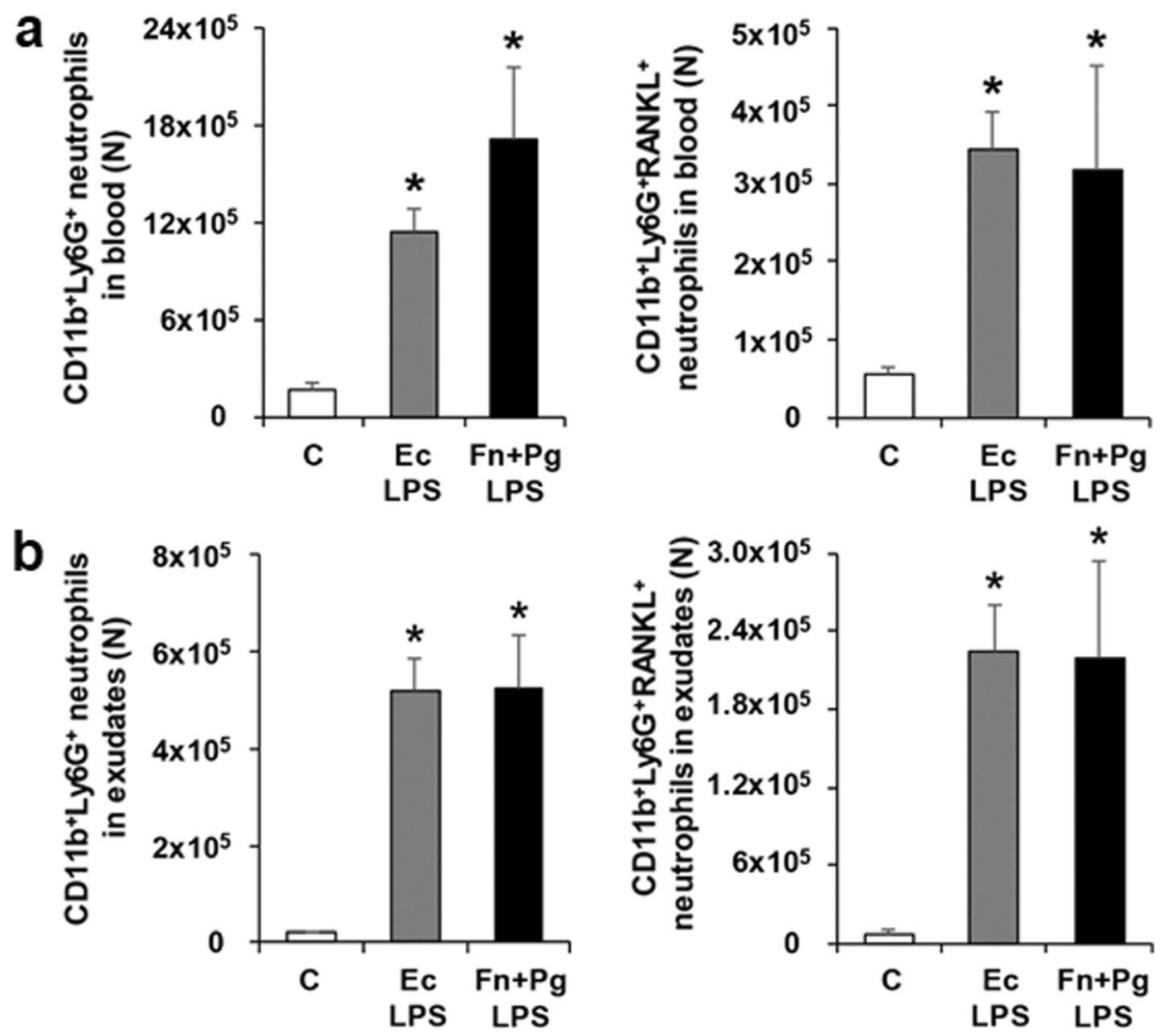

Fig. 4 Neutrophils and RANKL-expressing neutrophils in mice with Fn LPS and Pg LPS-injected air pouches. a Numbers of CD11 $b^{+} L y 6 G^{+}$ neutrophils and $C D 11 b^{+} L_{6} 6 G^{+} R A N K L^{+}$neutrophils in blood. $\mathbf{b}$ Numbers of $C D 11 b^{+} L_{6} 6 G^{+}$neutrophils and $C D 11 b^{+} L_{6} 6 G^{+} R A N K L^{+}$neutrophils in exudates. Data are presented as mean \pm SE. ${ }^{*} p<0.017$ vs C. C, control; Ec, Escherichia coli; Fn, Fusobacterium nucleatum; Pg, Porphyromonas gingivalis; LPS, lipopolysaccharide; N, number

expressing neutrophils could affect the progression of periodontitis. RANKL is an essential factor of osteoclast differentiation [13]. Increases of RANKL-expressing neutrophils under inflammatory conditions such as presence of periodontopathogen LPS in air porches suggest that RANKL-expressing neutrophils might be associated with osteoclast formation during periodontitis. An in vivo study is needed in the future to confirm the relationship between osteoclast formation and RANKL-expressing neutrophils during periodontitis.

\section{Conclusions}

These findings propose that periodontopathogen LPS act as a stimulant to increase RANKL-expressing neutrophils. This study is meaningful in that it reports the effect of periodontopathogen LPS on RANKL-expressing neutrophils.

\section{Abbreviations}

Ab: Antibody; C: Control; Ec: Escherichia coli; EDTA: Ethylene diamine tetra acetic acid; Fn: Fusobacterium nucleatum; LPS: Lipopolysaccharide;

$\mathrm{N}$ : Number; Pg: Porphyromonas gingivalis; RANKL: Receptor activator of NF-KB ligand; SE: Standard error
Acknowledgments

None

Authors' contributions

Kim AR participated in the animal experiment and drafted the manuscript. Lim YK and Kook JK participated in purification of Fn LPS. Bak EJ and Yoo YJ designed the study and drafted and revised the manuscript. All authors read and approved the final manuscript.

\section{Funding}

This work was supported by a National Research Foundation of Korea (NRF) grant funded by the Korean government (MIST) (NRF-2017R1A2B4002348).

Availability of data and materials

All the data generated or analyzed during this study are included in this published article.

\section{Competing interests}

The authors declare that they have no competing interests.

\section{Author details}

'Department of Oral Biology, College of Dentistry, Yonsei University, Seoul, Republic of Korea. ${ }^{2}$ Department of Applied Life Science, The Graduate School, Yonsei University, Seoul, Republic of Korea. ${ }^{3}$ BK21 PLUS Project, College of Dentistry, Yonsei University, Seoul, Republic of Korea. ${ }^{4}$ Korean Collection for Oral Microbiology and Department of Oral Biochemistry, School of Dentistry, Chosun University, Gwangju, Republic of Korea. 
Received: 30 July 2020 Accepted: 27 November 2020

Published online: 06 January 2021

\section{References}

1. Socransky SS, Haffajee AD, Cugini MA, Smith C, Kent RL Jr. Microbial complexes in subgingival plaque. J Clin Periodontol. 1998;25(2):134-44.

2. Socransky SS, Haffajee AD. Dental biofilms: difficult therapeutic targets. Periodontol. 2000;2002(28):12-55.

3. Bradshaw DJ, Marsh PD, Watson GK, Allison C. Role of Fusobacterium nucleatum and coaggregation in anaerobe survival in planktonic and biofilm oral microbial communities during aeration. Infect Immun. 1998; 66(10):4729-32.

4. Kolenbrander PE, Andersen RN, Moore LV. Coaggregation of Fusobacterium nucleatum, Selenomonas flueggei, Selenomonas infelix, Selenomonas noxia and Selenomonas sputigena with strains from 11 genera of oral bacteria. Infect Immun. 1989;57(10):3194-203.

5. de Andrade KQ, Almeida-da-Silva CLC, Coutinho-Silva R. Immunological pathways triggered by Porphyromonas gingivalis and Fusobacterium nucleatum: therapeutic possibilities? Mediators Inflamm. 2019;2019:7241312.

6. Hajishengallis G, Darveau RP, Curtis MA. The keystone-pathogen hypothesis. Nat Rev Microbiol. 2012;10(10):717-25

7. Wang X, Quinn PJ. Lipopolysaccharide: biosynthetic pathway and structure modification. Prog Lipid Res. 2010;49(2):97-107.

8. Wilkinson SG. Bacterial lipopolysaccharides-themes and variations. Prog Lipid Res. 1996;35(3):283-343.

9. Al-Qutub MN, Braham PH, Karimi-Naser LM, Liu X, Genco CA, Darveau RP. Hemin-dependent modulation of the lipid A structure of Porphyromonas gingivalis lipopolysaccharide. Infect Immun. 2006;74(8):4474-85.

10. Asai Y, Makimura Y, Kawabata A, Ogawa T. Soluble CD14 discriminates slight structural differences between lipid as that lead to distinct host cell activation. J Immunol. 2007;179(11):7674-83.

11. Yoshimura A, Hara Y, Kaneko T, Kato I. Secretion of IL-1 $\beta, T N F-a, I L-8$ and IL1 ra by human polymorphonuclear leukocytes in response to lipopolysaccharides from periodontopathic bacteria. J Periodontal Res. 1997; 32(3):279-86.

12. Cochran DL. Inflammation and bone loss in periodontal disease. J Periodontol. 2008;79(8 Suppl):1569-76.

13. Takahashi N, Udagawa N, Suda T. A new member of tumor necrosis factor ligand family, ODF/OPGL/TRANCE/RANKL, regulates osteoclast differentiation and function. Biochem Biophys Res Commun. 1999;256(3): 449-55.

14. Kassem A, Henning P, Lundberg P, Souza PP, Lindholm C, Lerner UH. Porphyromonas gingivalis stimulates bone resorption by enhancing RANKL (receptor activator of NF-kB ligand) through activation of Toll-like receptor 2 in osteoblasts. J Biol Chem. 2015;290(33):20147-58

15. Hu X, Sun $Y, X u$ W, Lin T, Zeng H. Expression of RANKL by peripheral neutrophils and its association with bone mineral density in COPD. Respirology. 2017:22(1):126-32.

16. Poubelle PE, Chakravarti A, Fernandes MJ, Doiron K, Marceau AA. Differential expression of RANK, RANK- $L$, and osteoprotegerin by synovial fluid neutrophils from patients with rheumatoid arthritis and by healthy human blood neutrophils. Arthritis Res Ther. 2007;9(2):R25.

17. Hajishengallis E, Hajishengallis G. Neutrophil homeostasis and periodontal health in children and adults. J Dent Res. 2014;93(3):231-7.

18. Silva LM, Brenchley L, Moutsopoulos NM. Primary immunodeficiencies reveal the essential role of tissue neutrophils in periodontitis. Immunol Rev. 2019;287(1):226-35.

19. Chakravarti A, Raquil MA, Tessier P, Poubelle PE. Surface RANKL of Toll-like receptor 4-stimulated human neutrophils activates osteoclastic bone resorption. Blood. 2009;114(8):1633-44.

20. Vandal K, Rouleau P, Boivin A, Ryckman C, Talbot M, Tessier PA. Blockade of S100A8 and S100A9 suppresses neutrophil migration in response to lipopolysaccharide. J Immunol. 2003;171(5):2602-9.

21. Swamydas M, Luo Y, Dorf ME, Lionakis MS. Isolation of mouse neutrophils. Curr Protoc Immunol. 2015;110:3.20.1-15.

22. Parkos CA. Molecular events in neutrophil transepithelial migration. BioEssays. 1997;19(10):865-73.

23. Lee PY, Wang JX, Parisini E, Dascher CC, Nigrovic PA. Ly6 family proteins in neutrophil biology. J Leukoc Biol. 2013;94(4):585-94.

24. Lu Q, Darveau RP, Samaranayake LP, Wang CY, Jin L. Differential modulation of human $\beta$-defensins expression in human gingival epithelia by
Porphyromonas gingivalis lipopolysaccharide with tetra- and penta-acylated lipid A structures. Innate Immun. 2009;15(6):325-35.

25. Gu JY, Liu YJ, Zhu XQ, Qiu JY, Sun Y. Effects of endotoxin tolerance induced by Porphyromonas gingivalis lipopolysaccharide on inflammatory responses in neutrophils. Inflammation. 2020;43(5):1692-706.

26. Darveau RP. Periodontitis: a polymicrobial disruption of host homeostasis. Nat Rev Microbiol. 2010;8(7):481-90.

\section{Publisher's Note}

Springer Nature remains neutral with regard to jurisdictional claims in published maps and institutional affiliations.
Ready to submit your research? Choose BMC and benefit from:

- fast, convenient online submission

- thorough peer review by experienced researchers in your field

- rapid publication on acceptance

- support for research data, including large and complex data types

- gold Open Access which fosters wider collaboration and increased citations

- maximum visibility for your research: over $100 \mathrm{M}$ website views per year

At $\mathrm{BMC}$, research is always in progress.

Learn more biomedcentral.com/submissions 